\title{
PARTICLE EXHAUST SCHEMES IN THE DIII-D ADVANCED DIVERTOR CONFIGURATION*
}

\author{
M. M. Menon and P. K. Mioduszewski \\ Oak Ridge National Laboratory, P.O. Box 2009. Oak Ridge. TN 37831 -8072
}

\begin{abstract}
For density control in long-pulse operation, the open divertor on the DIII-D tokamak will be equipped with a baffled chamber and a pumping system. The throat of the baffle chamber is sized to provide optimal pumping for the typical plasma equilibrium configuration. Severe limitutions on the toroidal conductance of this baffle chamber require the use of in-vessel pumping to achicve the desired particle exhaust of about 25 Torr-1/s. Two scparate pumping schemes are considered: an array of tutanium getuer modules based on the design developed by the Tore Supra team and a cryocondensation pump. The merits and demerits of each scheme are analyzed, and the design considerations introduced by the tokamak environment are brought out.
\end{abstract}

\section{INTRODUCTION}

To prevent density rise during long-pulse $\mathrm{H}$-mode discharges in DIII-D, it is estimated that the particle exhaust must be approximately equal to the particle input from cxtemal fucling. In DIII-D, this corresponds to about 25 Torr-1/s. In the DIII-D advanced divertor configuration, a baffled chamber with its throat close to the outboard strike region of the plasma is provided to urap and pump a fraction of the particles (Fig. 1). Based on DEGAS calculations of the pressure buildup in this chamber, a pumping speed of $\geq 50,000 \mathrm{l} / \mathrm{s}$ is nceded to achieve the desired particle exhaust [1]. However, the toroidal conductance of the baffle chamber, for a $1-\mathrm{m}$ long section, is only about $2000 \mathrm{~V} / \mathrm{s}$. The cross-scctional area of this tcroidal chamber cannot be increased to improve the conductance because this would adversely affect the maximum capability for high-current plasmas. The small (8-in.-diam) ports also hinder external pumping. In-vessel pumping is therefore necessary to achieve the desired pumping spced.

Two types of in-vessel pumping are considered: (1) a special type of titanium getter pump. based on a design

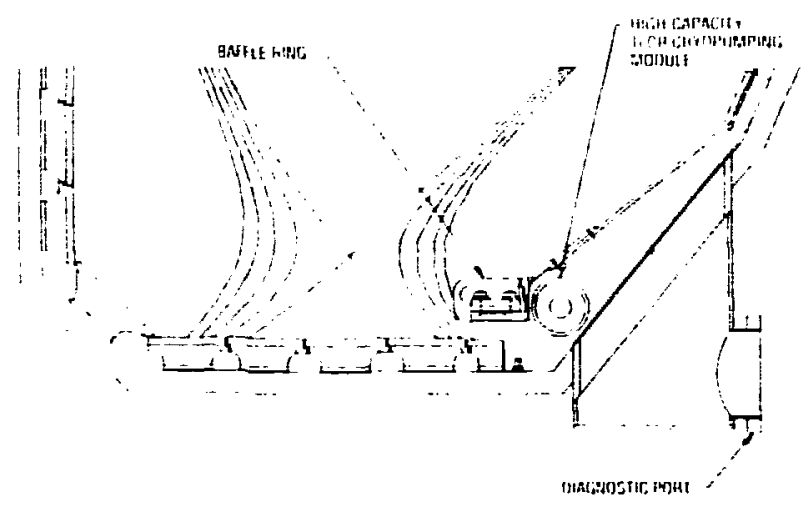

Fig. 1. Lucation of the baffle chamber and the pump in DIII-D.

developed for Tore Supra applications [2], and (2) a cryocondensation pump. The former has the advantage of being able to operate in a high-temperature environment. but its pumping characteristics are affected by residual gases. Also, the filament used to evaporate the titanium determines the life of the pump. On the other hand, the cryocondensation pump has well-known and predictable pumping characteristics, high pumping specd, high capacity, and the ability to regencrate the pumped gases. However, the high-lemperature environment, pressure ranges extending to milliTor, and problems arising from pulsed magnetic fields in tokamaks make the design of such a pump quite challenging. In what follows we claborate on the designs of these two pumps.

\section{TITANIUM GETTER PUMPS}

Ir this scheme, several getter modules are distributed toroidally inside the baffled chamber to provide pumping. Each modulc consists of a stack of disks on which titanium is deposited with a filament running axially along the disks (Fig. 2). Following the prescriptions in Ref. 121, a thick coating of titanium (about $S 0(X)$ monolaycrs or 1.7

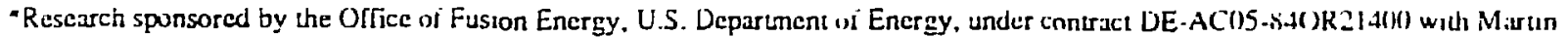
Maricta Energy Systems, Inc.
} 


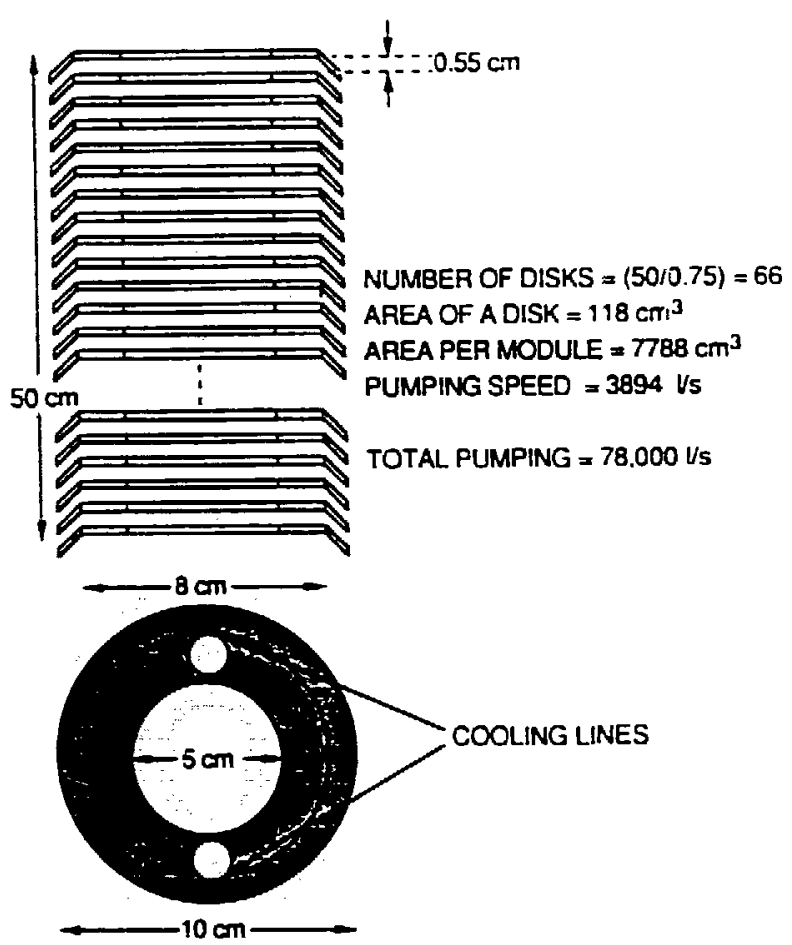

Fig. 2. Schematic of a getter pump modulc.

$\mu \mathrm{m}$ ) is evaporated from the filament onto the disks. The outer diameter of the disks is selected on the basis of available space in the gettcr chamber and is $10 \mathrm{~cm}$ in our preliminary design. The disks are bent at an angle 30 prevent titanium from escaping the getter stack. This angle is also affected by the spacing between the disks; the closer the disks, the greater the angle and therefore the lower the probability of a gas particle finding its way to the titanium-coated surface. Allother consideration is the variation in coating thickness. This variation increases as the disk spacing is reduced and desreases as the inticr diameter of the disks is increased. The angle that corresponds to the condition where there is no line of sight to the filament is

$\tan \theta=\left(R_{3}-R_{2}\right) d /\left[\left(R_{4}-R_{3}\right)\left(R_{3}-R_{2}\right)\right]$.

where $R_{2}$ is the intemal radius of the disk, $R_{3}$ is the radius where the disk is bent. $R_{\downarrow}$ is the external radius, and $d$ is the disk gap.

The ratio of titanium deposited at $R_{3}$ to that at $R_{2}$ is

$\mathrm{Q}_{3} / \mathrm{Q}_{2}=\left(\mathrm{R}_{2} / \mathrm{R}_{3}\right)\left(1-1 /\left(1+\left[\mathrm{d} /\left(\mathrm{R}_{3}-\mathrm{R}_{2}\right)\right]^{2}\right\}^{0.5}\right)$
A Monte Carlo code is being used to optinize the angle 0 and the spacing $l$. tween the disks.

For proper coating and to prevent overheating of the array, the disks are cooled during cuaporation. Degassing Is done by tuming off the cooling and using the same lilament to bake the disks to about $4\left(\mathrm{O}^{\circ} \mathrm{C}\right.$ for about $\mathrm{th}$ [2].

The pumping characterization perlormed by the Ture Supra group was limited to pressures lower than $10^{-5}$ wrr. We have measured the pumping speed at higher r.ressures by applying a thick coating $(0.9 \mu \mathrm{m})$ on the inn'r surfaces of a stainless steel chamber with a volume ci 6.31 and a surface area of $2000 \mathrm{~cm}^{2}$ under ultrahigh-vacuum conditions. The results are shown in Fig. 3. A pumping specd oî about $1.51 . \mathrm{s}^{-1} \cdot \mathrm{cm}^{-2}$ can be realized even at pressures approaching 1 mTorr. At the end of this experimental run, the gettered surfaces were left under vacuum $\left(8.8 \times 10^{-9}\right.$ Torr) over the weekend. Measurements carricd out after about $70 \mathrm{~h}$ showed that the pumping speed was reduced by a factor of about 20 . This reduction in pumping performance is attributed to poisoning by residual gases present in the ultrahighvacuum chamoer. Similar effects were reported by Druaux and Sledziewski [2], who also claim that the full pumping speed can be regained by applying a thin coat of titanium (about 200-300 monolayers) after degassing the disks. However, our attempt to rejuvenate the pumping characteristics of the thick layer mentioned above was only partially successful. The pumping speed measured after applying a thin coating of about 300 monolayers, following ovemight baking at temperatures up to $370^{\circ} \mathrm{C}$, decreased steadily with hydrogen loading (Fig. 4).

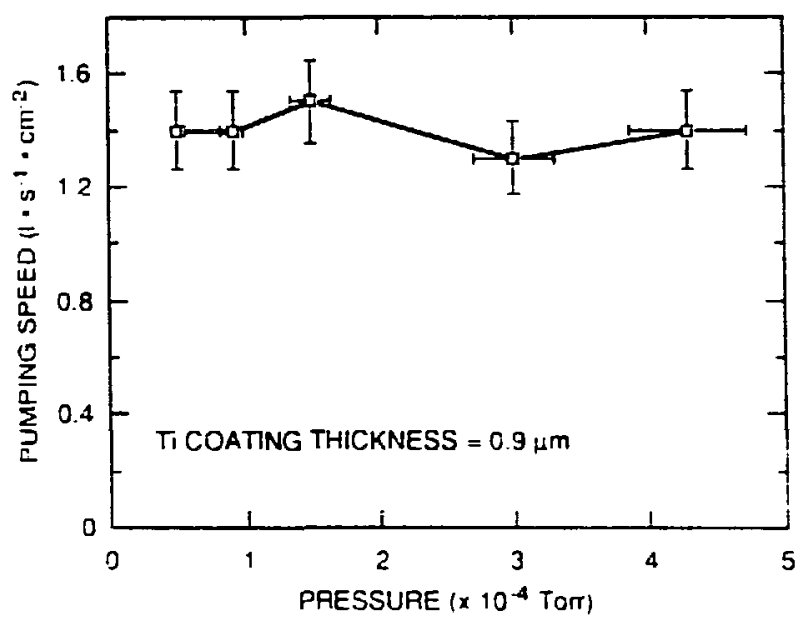

Fig. 3. PLmping speed vs pressurc for a thick (1).9- $\mu \mathrm{m})$ litanium layer. 


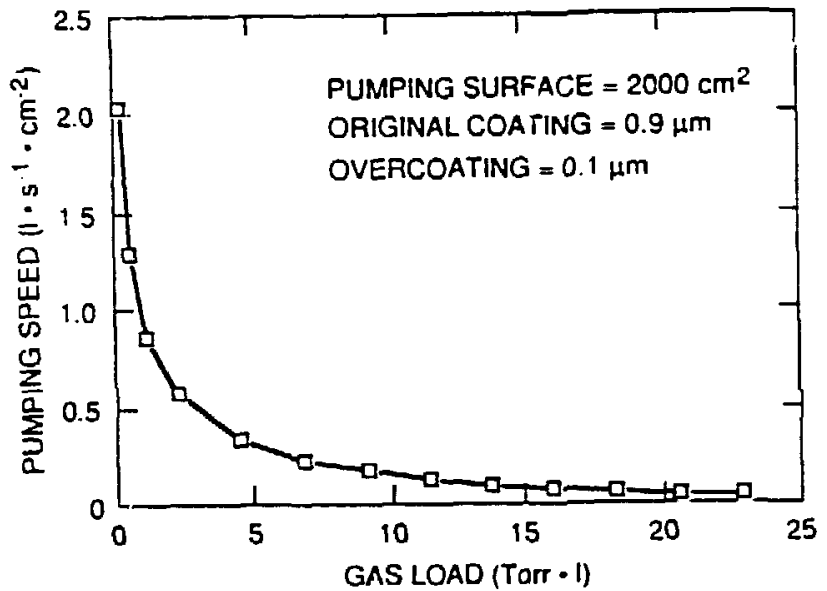

Fig. 4. Pumping speed vs hydrogen loading after poisoning and rejuvenation.

\section{CRYOCONDENSATION PUMP}

With a cryocondensation pump, the pumping surface is at liquid helium temperature, where the sticking coefficient for all gases except helium is close to unity. The pumping speed is reduced by the liquid-nitrogencooled chevron around the helium line. In our reference design, we consider a coaxial arrangement because of its simplicity. A standard $90^{\circ}$ chevron spaced to provide no direct line of sight to helium cuts down the pumping speed of a bare helium panel by a factor of 4 . Thus, a pumping speed of about $61 \cdot \mathrm{s}^{-1} \cdot \mathrm{cm}^{-2}$ can be realized for deuterium. The tornidal span for DIII-D is about $10 \mathrm{~m}$. Therefore, a liquid-helium-cooled surface of about 10,000 $\mathrm{cm}^{2}$ should provide the desired pumping of $>50,000 \mathrm{l} / \mathrm{s}$.

$A$ varicty of configurations can be envisioned for such a pump, and the search for an optimal geometry is under way. However, we base our analysis on the simple coaxial geometry shown schematically in Fig. 5. The heat loading from various factors obtained in this geometry can readily be applied to any other optimized configuration.

\section{Hent Loading on the Helium Line}

1. Radiation load: For two concentric cylinders with an outer surface area $A_{2}$ at temperature $T_{2}$ and an inner surface arca $A_{1}$ at temperature $T_{1}$, the radiation $Q$ to the inner cylinder is

$$
\begin{aligned}
Q / A_{1}= & \sigma_{S}\left(1 /\left\{\left(1 / \varepsilon_{1}\right)+\left(A_{1} / A_{2}\right)\left[\left(1 / \varepsilon_{2}\right)-1\right]\right\}\right) \\
& \left(T_{2}^{4}-T_{1}^{4}\right) .
\end{aligned}
$$

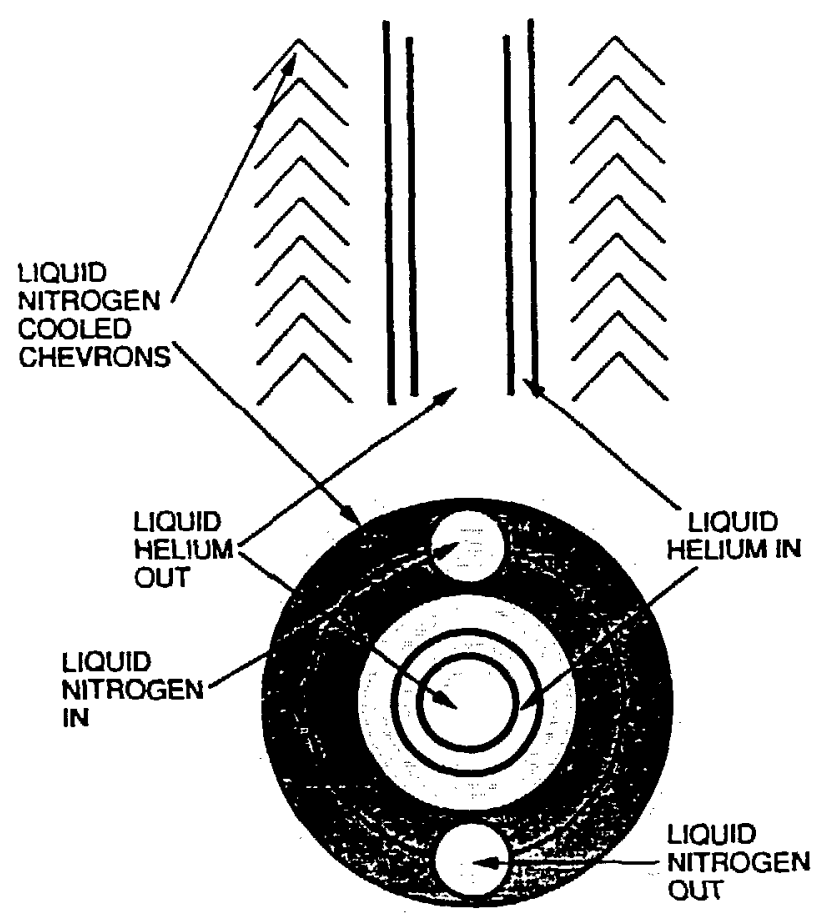

Fig. 5. Schematic of a cryocondensation pump.

where $\sigma_{\mathrm{s}}=5.7 \times 10^{-12} \mathrm{~W} / \mathrm{cm}^{2}$ is the StefanBoltzmann constant, and $\varepsilon_{1}$ and $\varepsilon_{2}$ are the emissivities of the two surfaces. For $\varepsilon_{1}=\varepsilon_{2}=1$ and $A_{1}=A_{2}$,

$$
\begin{aligned}
Q / A_{1} & =46 \mathrm{~mW} / \mathrm{cm}^{2} \text { for } T_{2}=300 \mathrm{~K}, \mathrm{~T}_{1}=77 \mathrm{~K}, \\
& =200 \mu \mathrm{W} / \mathrm{cm}^{2} \text { for } T_{2}=77 \mathrm{~K}, T_{1}=4.2 \mathrm{~K} .
\end{aligned}
$$

Thus, the total radiation load to the $10,000-\mathrm{cm}^{2}$ helium surface is $2 \mathrm{~W}$.

2. Conduction heal load: This is ineat transferred from the liquid nitrogen surface to the liquid helium line by way of solid supports and fitlings. The exact magnitude depends on the details of the design. The heat conducted from a surface at $T_{2}$ to a surface at $T_{1}$ through a body of uniform cross section and length $L$ is given by

$Q=(A / L) \int k d T$

For stainless stcel, $\mathrm{k}$ varics from $2.5 \times 10^{-3} \mathrm{~W} / \mathrm{cm}=\mathrm{K}$ at $4 \mathrm{~K}$ to $7.0 \times 10^{-2} \mathrm{~W} / \mathrm{cm}-\mathrm{K}$ at $77 \mathrm{~K}$. For cxample. the heat leak to the helium line from the nitrogen surface through a $1-\mathrm{cm}$-wide, 2 -cm-long, 1 -mm-thick 
stainlcss stcel strip is about $0.25 \mathrm{~W}$. Thus, by clever design, it should be possible to support the helium line with a heat leak of less than $5 \mathrm{~W}$. The end fittings usually coneribute a few more watts.

3. Particle load: If we assume completc thermalization of all the particles to liquid nitrogen temperature, for a pulsed load of 25 Torr $1 / \mathrm{s}$ lasting for $4 \mathrm{~s}$, there is a total of 100 Torr-l of gas or $3.6 \times 10^{21}$ particles. The heat load per pulse is then $3.6 \times 10^{21}[(3 / 2) \mathrm{kT}+$ the latent heat of fusion per particlel, where $T$ is $77 \mathrm{~K}$ (the boiling point of liquid nitrogen). This heat load amounts to about $4 \mathrm{~W} /$ pulse. In practice, the assumption of complete thermalization of all particles to $77 \mathrm{~K}$ is not realistic. Moreover, a significant number of plasma particies at energies of a few electron-volts actually strike the liquid nitrogen shield. The increase in heat loading from these particles has been estimated in a DEGAS calculation, and the contribution to the liquid helium surface is between 2 and $20 \mathrm{~W}$ [3]. The wide range in this number arises from uncertainitics in the refection models of particles at energies of a few clectron volts.

4. Heat loading due to eddy currents: This is dependent on the surface area and thickness of the helium line and the rate of change of the magnetic ficld. For a wire of radius $R$,

$\mathrm{P}_{\mathrm{e}}=(\pi \mathrm{R} \dot{3})^{2 / 4} \rho$

which, when extended to a tube with outer and inner radii $R_{0}$ and $R_{i}$, is given by

$$
P_{e}=\pi^{2} \dot{B}^{2}\left(R_{o}{ }^{2}-R_{i}{ }^{2}\right) / 4 \rho
$$

(in $W / \mathrm{m}^{3}$ ) where $\dot{B}$ is the rate of change in the magnetic field (in $\mathrm{Wb} / \mathrm{m}^{2}$ ) and $\rho$ is the resistivity (in $\Omega \cdot m)$. Thus, the total eddy losses are estimated to bc only $377 \mathrm{~mW}$ for a $10-\mathrm{m}$-long, 3 -cm-diam stainless steel line with $1-m m$-thick walls.

5. Induced voltage-driven load: If the cryogenic line has no insulating break, the voltage induced in the loop by the changing magnetic field will drive a current, thereby providing a heat load to the line. The loop voliage is decided by the operating conditions and can be up to $15 \mathrm{~V}$ in DITI-D. For a 10-m-long, 3-cmdiam stainless steel line with 1 -mm-thick walls, the resistance is $40 \mathrm{~m} \Omega$. The power dissipation due to induced voluge in the loop can thus be up to $250 \mathrm{~W}$. If a single loop is used, the line should be provided with insulating breaks.

6. Electron cuclotron hcaling (ECH) load: The power absorbed by a metal surface, assuming isotropic radiation, is

$P_{a b s}=P_{o}\left(8 R_{S} A_{S} B \eta\right)$,

with $R_{S}=(\pi f \mu / \sigma)^{1 / 2}$, where $f$ is the frequency $\left(s^{-1}\right)$, $\mu=4 \pi \times 10^{-7} \mathrm{H} / \mathrm{m}$ is the free-space permittivity , $\sigma$ is the conductivity (mho/m), $A_{S}$ is the surface arca,$\eta$ is $377 \Omega$, and $P_{0}$ is the power incident on the surface. Only about $10 \%$ of the ECH power will be dissipated on the walls, since plasma is a good absorber, and only a small fraction of this power will enter the baflle chamber. Some of the power that enters the oaffe chamber will be absorbed by the helium line. An exact calculation is difficult because of the multiple reflection at the walls, escape of energy through the windows of the vacuum vessel, etc.; a very crude estimate gives a power of less than $4 \ddot{w}$ for $2 \mathrm{MW}$ of ECH power.

7. Neutron loading: If the neutron production rate is $10^{15} \mathrm{~s}^{-1}$, the neutron loading on the helium line is less than $10 \mathrm{~mW}$ for a 3 -cm-diam line with a surface arca of $10,000 \mathrm{~cm}^{2}$.

\section{Heat Loading on the Liquid Niurngen Circuit}

If the bafnc plate is not water cooled and its temperature reaches $200^{\circ} \mathrm{C}$, then the radiation load to the nitrogen line is by far the main contributor and is about $2.8 \mathrm{~W} / \mathrm{cm}^{2}$.

\section{Qther Design Considerations}

1. Glow discharge cleaning of the tokamak: The DIII-D tokamak operating scenario involves helium glow discharge cleaning between shots. The pressure during glow is typically $2 \mathrm{mTor}$, and it is hoped to operate at a reduced pressure of $1 \mathrm{mTorr}$ with clectron-assisted glow. We can calculate the arrival rate to be $3.5 \times 10^{22} / \mathrm{p} /(\mathrm{MT})^{0.5} \mid \mathrm{per}$ square centimeicr (for $p$ in Tort). If the helium gas at $T_{l}$ is 
completely thermalized to liquid nitrogen temperature $\mathrm{T}_{2}$, the pressure inside the nitrogen surface is

$\mathrm{p}_{1} / \mathrm{p}_{2}=\left(\mathrm{T}_{1} / \mathrm{T}_{2}\right)^{0.5}$

Thus, the arrival rate at the liquid helium surface is

$$
\begin{aligned}
& 3.5 \times 10^{22}\left[\mathrm{p}_{1}\left(\mathrm{~T}_{2} / \mathrm{T}_{1}\right)^{0.5} /\left(\mathrm{MT}_{2}\right)^{0.5}\right] \\
& =3.5 \times 10^{22}\left[\mathrm{p}_{1} /\left(\mathrm{MT}_{1}\right)^{0.5} \mathrm{l}\right.
\end{aligned}
$$

For $\mathrm{p}=1 \mathrm{~m}$ Torr, the arrival rate is $9.8 \times 10^{17} \mathrm{Hc}$ molccules $/ \mathrm{cm}^{2}-\mathrm{s}$, and the heat input to the helium is cqual to the arrival rate times $1.5 \mathrm{kT}$, which is $1.56 \mathrm{~mW} / \mathrm{cm}^{2}-\mathrm{m}$ Tort. Thus, for a line with an area of $10,000 \mathrm{~cm}^{2}$, the heat loading during a helium glow discharge at $2 \mathrm{~m}$ Torr could be $31.2 \mathrm{~W}$. lasting for several minutes. In practice, this figure will be higher, becausc our assumption of complete thermalization of all particles to $77 \mathrm{~K}$ is not realistic for normal Iypes of chevrons.

A more serious thermal load to the helium line occurs during the helium gas ining to initiate the glow. In present experiments, the pressure is raised instantancously to $50 \mathrm{mTorr}$, when the discharge strikes, it is brought down with an c-folding time of $10 \mathrm{~s}$. Based on the rate of $15.6 \mathrm{~W} / \mathrm{mT}$ Torr, we can see the equivalent of a few hundred watts of heat loading lasiung for a few seconds. Morcover, since the mean frec path of helium at $50 \mathrm{~m}$ Torr is only $2.6 \mathrm{~mm}$, many particles al the bafle wall temperature will find the way to the helium line without entente on the nitrogen chevron, therehy increasing the heal input by a factor of about 5 . This heat load of ahout $1 \mathrm{~kW}$ (I) the helium line lasting for a lew seconds will be the determining factor in the design of the eryogenic loop.

2. Disruption forces on lle crvopump: These forces: arise from the interaction of currents induced in the line with the magnetic field perpendicular to it (.J $\times \mathbf{B}$ force). An estimate of the force would require details of the disruption conditions and of the pump.

\section{ACKNOWLEDGMENTS}

The authors are grateful for help provided by J. E. Simpkins during gettering experiments. Discussions with P. Bonnel, D. Hill, G. Jackson, A. Lunghom A. Maholavi, M. Schaffer, and $M$. Tupper were quite valuahle.

\section{REFERENCES}

11] L. W. Owen and P. K. Mioduszcwski, Oak Ridge National Laboratory, persunal communication, 1989.

(2) Z. Sledziewski and J. Druaux, "Titanium Getter Pumps for the Tore Supra Neutral Beam Lines," in Fusion Technology 1986: Procecdings of the $1+1 h_{l}$ Symposium, Avignon, 1986, vol. 1, pp. 533-38.

[3] L.W. Owen and P. Mioduzewski, unpublished.

\section{DISCLAIMER}

This report was prepared as an account of work sponsored by an agency of the United Siates Government. Neither the United States Government nor any agency thereof, nor any of their employees, makes any warranty, express or implied, or assumes any legal liability or responsibility for the accuracy, completeness, or usefulness of any information, apparatus, product, or process disclosed. or represents that its use would nol infringe privately owned rights. Reference herein to any specific commercial product, process, or service by trade name, trademark. manufacturer, or otherwise does not necessarily constitute or imply its endorsement, recommendation. or favoring by the United States Government or any Agency thereof. The views and opinions of authors expressed herein do not necessarily siate or reflect those of the United States Government or any agency thereof. 